\title{
Puritan Preachers in the Hands of Statisticians: The Stylometric Study of Colonial Religious Writings
}

\section{Introduction}

This article presents the overview of an OPUS research project "The Language of Eighteenth-Century American Colonial Sermons. A Rhetorical and Stylometric Analysis" (2014/13/B/HS2/00905), carried out in the Institute of English Studies at the Jagiellonian University. Upon putting together their proposal, the two authors of the project were quite aware, from the very start, that their proposal may raise some eyebrows on both sides of the Atlantic-why should the (predominantly Catholic) Polish taxpayer be asked to fund a venture that would look into the work of the $18^{\text {th }}$ century Puritan preachers from Colonial America? And yet, the Board of Poland's National Science Centre consented to the proposal and agreed to finance the project, which lasted altogether three years (20152018), and in which for the first time, in Poland, a quantitative approach to textual material from American early modern letters was applied. This interdisciplinary alliance of two methodologies: the stylometric study of the authorship signal that is part of the much more general field of digital humanities on the one hand, and historical-rhetorical approach to text on the other, demonstrates how the qualitative and quantitative may be reconciled, and how the synthesis of the divine and the digital may contribute to the existing scholarship on colonial religious history.

The purpose of this essay is to present the research approach used in that OPUS project, as well as the overall results of the application of quantitative methods to the corpus of colonial revival sermons, paying particular attention to the oeuvre of Jonathan Edwards, one of the central figures of the first Great Awakening. Three stylometric experiments are described below. In the first one, various texts of a group of colonial preachers are compared and contrasted with the help of stylometric tools to show possible intertextual affinities between particular authors. In the second experiment, the writings of Jonathan Edwards are classified into groups, in connection with how his stylometric signal changed over his life. Finally, applying a similar approach to individual works, the authors of the article study the extent to which Edwards's writings were informed by the style of his editor, Thomas Foxcroft-also, seeking to pinpoint the sections 
of his treatises that were most heavily augmented by Foxcroft (if not written entirely by him).

\section{The Stylometric Approach}

Stylometry has been used in textual studies even before the advent of computers, mainly in authorship attribution and plagiarism detection ${ }^{1}$ but also in Platonic chronology. ${ }^{2}$ Stylometric research projects became even easier to conduct with computers; ${ }^{3}$ the growing availability of electronic texts triggered a veritable explosion of the field into quantitative literary studies that go beyond authorship ${ }^{4}$ and into Distant Reading. ${ }^{5}$ In general, stylometry calculates the features of texts -often very simple features, such as word- or character- or part-of-speech-frequencies-and shows the linguistic or indeed stylistic differences between texts, authors, or groups of authors.

The above-cited seminal work by Mosteller and Wallace used function word counts to give a convincing answer to the question of the authorship of pamphlets urging citizens of New York to ratify the Constitution of the United States. ${ }^{6}$ Burrows applied an analogous method to show the similarity of frequent-word usage in the idiolects of similar characters in Jane Austen. ${ }^{7}$ Hoover demonstrates

1 E.g., Thomas C. Mendenhall, “A Mechanical Solution of a Literary Problem,” The Popular Science Monthly, 1903.

2 Wincenty Lutosławski, The Origin and Growth of Plato's Logic: With an Account of Plato's Style and of the Chronology of His Writings (London: Longmans, Green, and Co., 1897).

3 E.g., Frederick Mosteller and David L. Wallace, Inference and Disputed Authorship (Reading, MA: Addison-Wesley, 1964).

4 E.g., John Frederick Burrows, Computation Into Criticism: A Study of Jane Austen's Novels and an Experiment in Method (Oxford: Clarendon Press, 1987); David L. Hoover, "A Conversation Among Himselves: Change and the Styles of Henry James," in Digital Literary Studies: Corpus Approaches to Poetry, Prose, and Drama, ed. David L. Hoover, Jonathan Culpeper, and Kieran O’Halloran (New York and London: Routledge, 2014), 90-119; Jan Rybicki, “The Great Mystery of the (Almost) Invisible Translator: Stylometry in Translation," in Quantitative Methods in Corpus-Based Translation Studies: A Practical Guide to Descriptive Translation Research, ed. Michael P. Oakes and Ji Meng (Amsterdam: John Benjamins Publishing Company, 2012), 231-48; and Jan Rybicki, "Vive La Différence: Tracing the (Authorial) Gender Signal by Multivariate Analysis of Word Frequencies,” Digital Scholarship in the Humanities 31, no. 4 (2015): 746-61, https://doi. org/10.1093/llc/fqv023.

5 Matthew L. Jockers, Macroanalysis: Digital Methods and Literary History (Urbana: University of Illinois Press, 2013).

6 Mosteller and Wallace, Inference and Disputed Authorship.

7 Burrows, Computation Into Criticism. 
a very clear evolution of frequent-word frequencies throughout the oeuvre of Henry James. ${ }^{8}$ The same frequencies seem to preserve the signal of the original author rather than the translator in literary translations; ${ }^{9}$ medium frequency words, on the other hand, are good indicators of authorial gender. ${ }^{10}$ Jockers' work explores the various stylometric signals in large textual corpora, seeking to investigate entire literary traditions, and thus asking questions that cannot be readily answered by traditional close reading. ${ }^{11}$ The authors of this article themselves have applied the stylometric method for the study of American literature-among others, to discuss the authorship of Harper Lee's second novel, Go Set a Watchman, when its much-awaited release was surrounded by controversy. ${ }^{12}$ Many more examples could be mentioned here; indeed, the field has produced a good volume of compelling empirical data-and relatively little by way of theoretical basis for the results. The one consensus is that "the possibility of using frequency patterns of very common words (may) rest upon the fact that words do not function as discrete entities. Since they gain their full meaning through the different sorts of relationship they form with each other, they can be seen as markers of those relationships and, accordingly, of everything that those relationships entail."13

One of the standard procedures in stylometry by most frequent words serves as the basis for a software package, "stylo," ${ }^{14}$ written for R, the open-source statistical programming environment. ${ }^{15}$ For the research procedure to be carried out, the first thing needed, of course, is a collection of texts. In the case of this study, the writings by Jonathan Edwards constituted the core of the studied material. For the purpose of this OPUS project, access to the complete collection of works authored by the Northampton minister was offered by the Jonathan Ed-

8 Hoover, "A Conversation Among Himselves: Change and the Styles of Henry James."

9 Rybicki, "The Great Mystery of the (Almost) Invisible Translator: Stylometry in Translation." 10 Rybicki, "Vive La Différence."

11 Jockers, Macroanalysis.

12 Jan Rybicki, Maciej Eder, and Michał Choiński, "Harper Lee and Other People: A Stylometric Diagnosis,” The Mississippi Quarterly 70 -71, no. 3 (June 22, 2017): 355-75.

13 Wayne Mckenna, John Burrows, and Alexis Antonia, "Beckett's Trilogy: Computational Stylistics and the Nature of Translation," Revue Informatique et Statistique Dans Les Sciences Humaines 35, no. 1-4 (1999): 152.

14 Maciej Eder, Jan Rybicki, and Mike Kestemont, "Stylometry with R: A Package for Computational Text Analysis,” The R Journal 8, no. 1 (2016).

15 R Core Team, R: A Language and Environment for Statistical Computing, 2014, http://www.Rproject.org/. 
wards Center at Yale University; ${ }^{16}$ the writings of other early modern authors were also used for comparison; these were extracted from Early American Imprints. Once such a corpus of texts was produced in electronic form, the frequencies of all the words were counted, first in the corpus, then in all individual texts. In this way, the selection of the words used in the experiment (usually, the first 100 , the first 200, the first 300, etc.) is not performed by the researcher; instead, it is established by the corpus itself. In most English texts, the first five of these MFWs will invariably include the, to, and and and only very small differences in frequency rank will be observed between their usage in individual texts; but it is through those small differences that a surprising amount of comparative information is often revealed.

Of course, these numbers are not yet useful for any comparison, since they constitute raw rather than relative values. They must now be made relative to the size of each text. The easiest way to do so would be to divide each word-type frequency count by the size, in word tokens, of each text, and this was the approach applied by Burrows in his above-cited Jane Austen study; later on, however, he produced a more sophisticated formula that converted such raw word frequencies into a measure of distance (or dissimilarity) between texts. Indeed, Burrows's Delta distance became a standard in stylometry. ${ }^{17}$ Thus, for two texts, $\mathrm{T}$ and $\mathrm{T} 1$, and for a set of $\mathrm{n}$ words, the distance (the degree of similarity/difference) between them is calculated as

$$
\Delta\left(T, T_{1}\right)=\frac{1}{n} \sum_{x=1}^{n}\left|z\left(f_{i}(T)\right)-z\left(f_{i}\left(T_{1}\right)\right)\right|
$$

where

$$
z\left(f_{x}(T)\right)=\frac{f_{x}(T)-\mu_{x}}{\sigma_{x}}
$$

where, in turn,

$\mathrm{f}_{\mathrm{x}}(\mathrm{T})=$ raw frequency of word $\mathrm{x}$ in text $\mathrm{T}$;

$\mu_{\mathrm{x}}=$ mean frequency of word $\mathrm{x}$ in a collection of texts;

$\sigma_{\mathrm{x}}=$ standard deviation of frequency of word $\mathrm{x}$.

16 The authors of the article would like to use this opportunity to express their gratitude to Prof. Kenneth Minkema, the director of the Jonathan Edwards Center at Yale University for his willingness to share the edited corpus of Jonathan Edwards's writings.

17 John Burrows, “'Delta': A Measure of Stylistic Difference and a Guide to Likely Authorship,” Literary and Linguistic Computing 17, no. 3 (September 1, 2002): 267-87, https://doi.org/10.1093/ llc/17.3.267. 
To express this in words rather than in algebra, Delta is the mean of the absolute differences between the z-scores for a set of word-variables in a given textgroup and the z-scores for the same set of word-variables in a target text. This is obviously a much better distance measure since, by inserting mean frequencies and standard deviations, one can arrive at a much better account of the frequency distributions in the texts studied than mere relative frequencies. When strings of frequencies are compared between all the texts in a set, this produces another table, which contains the Delta distances between each pair of texts, not unlike a table of distances between cities at the back of a country's road atlas. Just as such a table would provide the distance between, say, New York and Washington, D.C., the table now shows, in a numerical fashion, the distance (or the degree of dissimilarity), between each pair of texts in the corpus. Indeed, just as these distances between American cities could be used by statistical methods to reproduce the general shape of the U.S., sets of distances between texts help classify and organize individual texts in relation to each other on graphs.

At this point, various statistic methods can help to visualize such a system of distances. One of these is Cluster Analysis. It compares strings of numbers denoting the distances between the individual texts that cluster around the nearest neighbours (texts) on branches of a tree diagram. The existing literature shows that this works for most (literary) texts in most languages ${ }^{18}$-at least where the strongest signal, that of authorship attribution, is concerned.

Sometimes, however, minor differences may appear between results obtained for different sizes of the most-frequent-word list; for instance, results for the first 100 words can be identical with those for the first 200 words; but then slight changes may start appearing with increasing wordlist length. There is a way around this dilemma-Cluster Analysis is performed for various wordlist sizes and the results are pooled in what is a called a Bootstrap Consensus. This method only shows the strongest connections between the texts in the corpus. Still, both Cluster Analysis and its Bootstrap Consensus share a common drawback. Namely, they only provide binary answers, like text A is closest to text B; text $\mathrm{C}$ is closest to text $\mathrm{D}$, etc. Such an outcome does not say much about the degree of similarity or difference between A and C, and B and D. And, obviously, such an outcome is not satisfactory in literary or historical studies. For instance, one author can be similar almost equally to two different authors, and this might not show up in the diagram produced. Luckily, network analysis, using software

18 For a comparative study of this phenomenon, see Maciej Eder and Jan Rybicki, "Do Birds of a Feather Really Flock Together, or How to Choose Training Samples for Authorship Attribution," Literary and Linguistic Computing 28, no. 2 (June 1, 2013): 229-36, https://doi.org/10.1093/llc/ fqs036. 
such as Gephi ${ }^{19}$ can produce diagrams that preserve all signals-not just the strongest one. And this is exactly how the research conducted under the auspices of the OPUS grant was carried out. This procedure, from electronic text input to obtaining network analysis graphs, is most comprehensively described and discussed by Eder. ${ }^{20}$

\section{The Historical Context}

A larger part of the corpus of texts studied in the OPUS project is connected with the Great Awakening (1739 - 1745), the first mass-scale Puritan revival of America. During that time, building upon a series of revivals from the mid-1730s, a group of itinerant preachers was able to impact crowds of thousands of people, instigating emotional reactions which often bordered on mass hysteria. This propelled the development of new forms of preaching, which manifested the power of the spoken word to colonists and fuelled the public debate. ${ }^{21}$ This context accounts for why the project's corpus consisted predominantly of sermons.

In colonial communities, sermons played a significant role, both social and religious. As observed by Harry Stout, ${ }^{22}$ they were the mass media of the period and functioned as the only regular medium of social debate. It is calculated that during the entire colonial period, when the population of colonies never reached beyond 1.5 million and in the largest city, Boston, lived 17,000 inhabitants, almost 5 million sermons were delivered. Preaching permeated the culture of the time and reflected the current social, intellectual, religious, and political debates.

Also, the Great Awakening impacted the colonial print culture. With the ongoing discussion about the status and the ramifications of the Great Awakening for the spiritual and public functioning of the colonies, a plethora of publications appeared. The most vitriolic debate erupted between the Old Lights (the critics of the revival) and the New Lights (its proponents). Little wonder that

19 Mathieu Bastian, Sebastien Heymann, and Mathieu Jacomy, "Gephi: An Open Source Software for Exploring and Manipulating Networks," in Proceedings of the International AAAI Conference on Web and Social Media, vol. 3:1, 2009.

20 Maciej Eder, “Does Size Matter? Authorship Attribution, Small Samples, Big Problem,” Digital Scholarship in the Humanities 30, no. 2 (2015): 167-82.

21 Cf. Michał Choiński, The Rhetoric of the Revival: The Language of the Great Awakening Preachers (Göttingen: Vandenhoeck \& Ruprecht, 2016).

22 Harry S. Stout, The New England Soul: Preaching and Religious Culture in Colonial New England (New York: Oxford University Press, 1986), 3. 
in the second half of the twentieth century, a number of commentators began approaching the revival also as a critical historical event that informed the American Revolution, ${ }^{23}$ shaped colonial culture and aesthetics ${ }^{24}$ as well as the significance of religion in the society. ${ }^{25}$ Also, literature on the silhouettes of the key proponents of the Great Awakening has grown opulent in the last four decades and the life and output of such preachers as Jonathan Edwards, ${ }^{26}$ George Whitefield $^{27}$ or Gilbert Tennent ${ }^{28}$ were discussed.

Surprisingly, until recently, only a few of these studies investigated the language-related aspects of colonial revivalism. In his article surveying different publications on the Great Awakening, Guelzo observed that "the rhetorical meanings of the Awakening are far from well understood." 29 The idea to analyse the texts of sermons stylometrically was a chance for a better understanding of linguistic aspects of the revival and the communicative mechanisms employed by the preachers to propagate the idea of the "New Birth." Most importantly, such an approach can empirically determine the connections between the styles of particular preachers and yield results that could not be obtained by manual analysis, driven only by the naked human eye.

The OPUS research grant reported on in this essay is not the only DH project dedicated to the study of the colonial religious discourse. For instance, in his research on Edwards, Rob Boss uses exegetic visualizations to study the interrelations between various theological concepts in the preacher's "Miscellanies." Boss's “Miscellanies Project” (2018), carried out with JESociety, aims to create a library of visualizations which comprehensively map theological topics found in Edwards's notebooks and the rest of the Yale letterpress edition of The Works of Jonathan Edwards. These network maps can be dynamically ex-

23 Alan Heimert, Religion and the American Mind: From the Great Awakening to the Revolution (Cambridge: Harvard University Press, 1966).

24 Edwin S. Gaustad, The Great Awakening in New England (New York: Harper, 1957); Cedric B. Cowing, The Great Awakening and the American Revolution: Colonial Thought in the 18th Century (New York: Rand McNally, 1971).

25 Mark A. Noll, The Rise of Evangelicalism: The Age of Edwards, Whitefield and the Wesleys (Downers Grove: InterVarsity Press, 2003).

26 E. g., George M. Marsden, Jonathan Edwards: A Life (New Haven: Yale University Press, 2003). 27 Harry S. Stout, The Divine Dramatist: George Whitefield and the Rise of Modern Evangelicalism (Grand Rapids: Wm. B. Eerdmans Publishing Co., 1991).

28 Milton J. Coalter, Gilbert Tennent, Son of Thunder: A Case Study of Continental Pietism's Impact on the First Great Awakening in the Middle Colonies (New York: Greenwood Press, 1986). 29 Allen Guelzo, “God's Designs: The Literature of the Colonial Revival of Religion, 1735-1760," in New Directions in American Religious History, ed. Harry S. Stout and D.G. Hart (New York: Oxford University Press, 1997), 162. 
plored, annotated, and animated with the accompanying JEViewer software and its Zoom interface. JEViewer also enables easy data exchange between users so that they can share annotations and graphical views. Such digital exegesis is but one of numerous examples of how DH methodologies can contribute to the existing scholarship on early modern religious discourse.

\section{Stylometric Network of Colonial Preachers}

The first experiment conducted as part of the OPUS research grant consisted in the comparative study of a group of preachers: Solomon Stoddard (1643-1729), Samuel Sewall (1652-1730), Benjamin Colman (1673-1747), Thomas Prince (1687-1758), Jonathan Dickinson (1688-1747), Nathaniel Appleton (16931784), Jonathan Edwards (1703-1758), Gilbert Tennent (1703-1764), Jonathan Parsons (1705-1776), Eleazar Wheelock (1711-1779), George Whitefield (17171770), Joseph Bellamy (1719-1790) and Ezra Stiles (1727-1797). All the preachers selected for this preliminary study were connected with the Great Awakening-either by being its active participants and later defendants, or by instigating the pre-revival "harvests" of conversions in the Connecticut River Valley in the 1730s. For the purpose of this initial experiment, plain text files with collections of their sermons were prepared-in the cases of preachers, whose writings were particularly extensive (in Figure 1, this concerns Whitefield and Edwards), these were divided into smaller collections, respective of the decades when the given sets of sermons were delivered.

Figure 1 demonstrates, among other things, the extent to which the sermons of Edwards and Stoddard, Edwards's grandfather, show stylometric resemblance. Such a statistically-derived result is hardly surprising from the perspective of qualitative analysis. Sweeney points out that Stoddard "cast[s] a mighty long shadow over Edwards' ministry"30 and his impact on the young Jonathan's "ministry of words" was formative. Stoddard, dubbed the "Pope" of the Connecticut River Valley, gained repute as an uncompromising revivalist who preached hellfire, and who, at the same time, demonstrated a liberal approach in the controversy over the Half-Way Covenant. In 1725, Jonathan Edwards received a proposal to become an assistant to Stoddard, and, upon the latter's death in 1729, took over the Northampton congregation. Edwards did not approve of Stoddard's leniency over the admission to church membership and the sacrament of the

30 Douglas A. Sweeney, Jonathan Edwards and the Ministry of the Word: A Model of Faith and Thought (Downers Grove: InterVarsity Press, 2009), 34. 
Lord's Supper, and swiftly implemented much stricter rules in this respect; in terms of preaching, however, he looked up to the authority and rhetorical prowess commanded by his grandfather with great reverence.

Curiously, the software placed Appleton's late sermons and Dickinson's early sermons not far away from the Edwards-Stoddard cluster. And, the late discourses of Parsons, Wheelock, and Stiles were put relatively close to one another. Such empirical results encourage a direct comparative reading of sermons by these authors, seeking to explain the affinity of stylometric signals by the investigation of the rhetorical mechanisms they employ. Likewise, the significant resemblance between the stylometric signals of Parsons, Prince, Stiles, and Wheelock detected by the software encourages a closer comparative study of the sermons by these preachers.

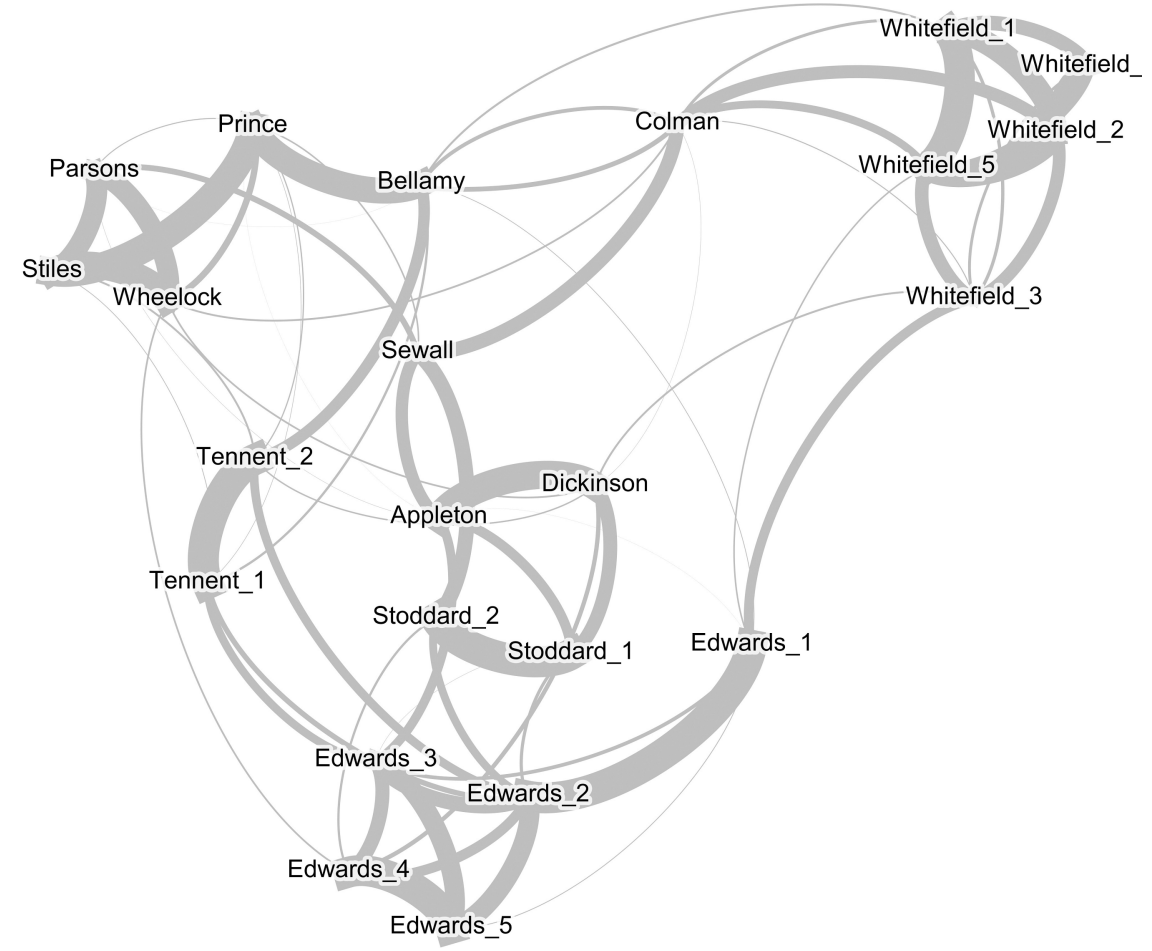

Figure 1: Network analysis showing stylometric differences between a group of American colonial preachers regarding the most-frequent-word usage.

Not all results presented in Figure 1 are equally unexpected. For instance, Whitefield's numerous sermons constitute a network cluster far removed from that of 
Edwards and Stoddard. The readers acquainted with the Great Awakening sermons should not be surprised by such an outcome. Although Edwards and Whitefield are, arguably, the most recognizable figures of the Great Awakening and remain most directly associated with the revival enthusiasm of the 1740s in the Colonies, their sermons are completely dissimilar. Whitefield, as a "divine dramatist," 31 was famous for his pulpit performance, and relied predominantly on preaching theatrics for his communicative success. His sermons abound in dialogues, evocative rhetorical figures, and organizational structures that remind one of theatre. Edwards, on the other hand, is a painter of words-for whom the theological message framed in elaborate tropological structures would become the recognized rhetorical trademark-as argued by Turnbull, "by Puritan standards Edwards's sermons are works of art."32

\section{Stylometric Study of Edwards's Corpus}

For the purpose of the second experiment, the complete corpus of Edwards's texts was divided into groups that follow the division of volumes introduced by the Yale editors of the Complete Works of Jonathan Edwards. Next, the files were labeled in such a way as to allow for a clear interpretation of the results on the diagram. The key phrases point to titles (e.g., Affections stands for the treatise Religious Affections), single capitals signal the genre of the texts ( $\mathrm{T}$ stands for treatises, L for letters and S for sermons), and, finally, dates point to the publication year. The greatest interest of a stylometric study on such a corpus was to see whether most-frequent-word usage might reflect the traditional division, and to check if indeed, as argued by the editors of his texts, "his sermons reflect the stages of his busy life."33

In Figure 2, one can clearly see that the stylometric survey of our Edwards corpus revealed five distinct groups of writings. The first cluster (C1) of texts visible in the top left part of the diagram includes Edwards's letters and private writings. Interestingly, here, his Personal Narrative, as well as The Life of David Brainerd (Edwards's biography of an early $18^{\text {th }}$ century missionary to the Native Americans) turn out to be the most remote from the rest of the corpus. Slightly less distinct, drifting gradually towards other groups, are family letters and cor-

31 Cf. Stout, The Divine Dramatist.

32 Ralph G. Turnbull, Jonathan Edwards: The Preacher (Grand Rapids: Baker Book House, 1958), 44.

33 Wilson H. Kimnach, Kenneth P. Minkema, and Douglas A. Sweeney, eds., The Sermons of Jonathan Edwards: A Reader (New Haven: Yale University Press, 1999), 1. 


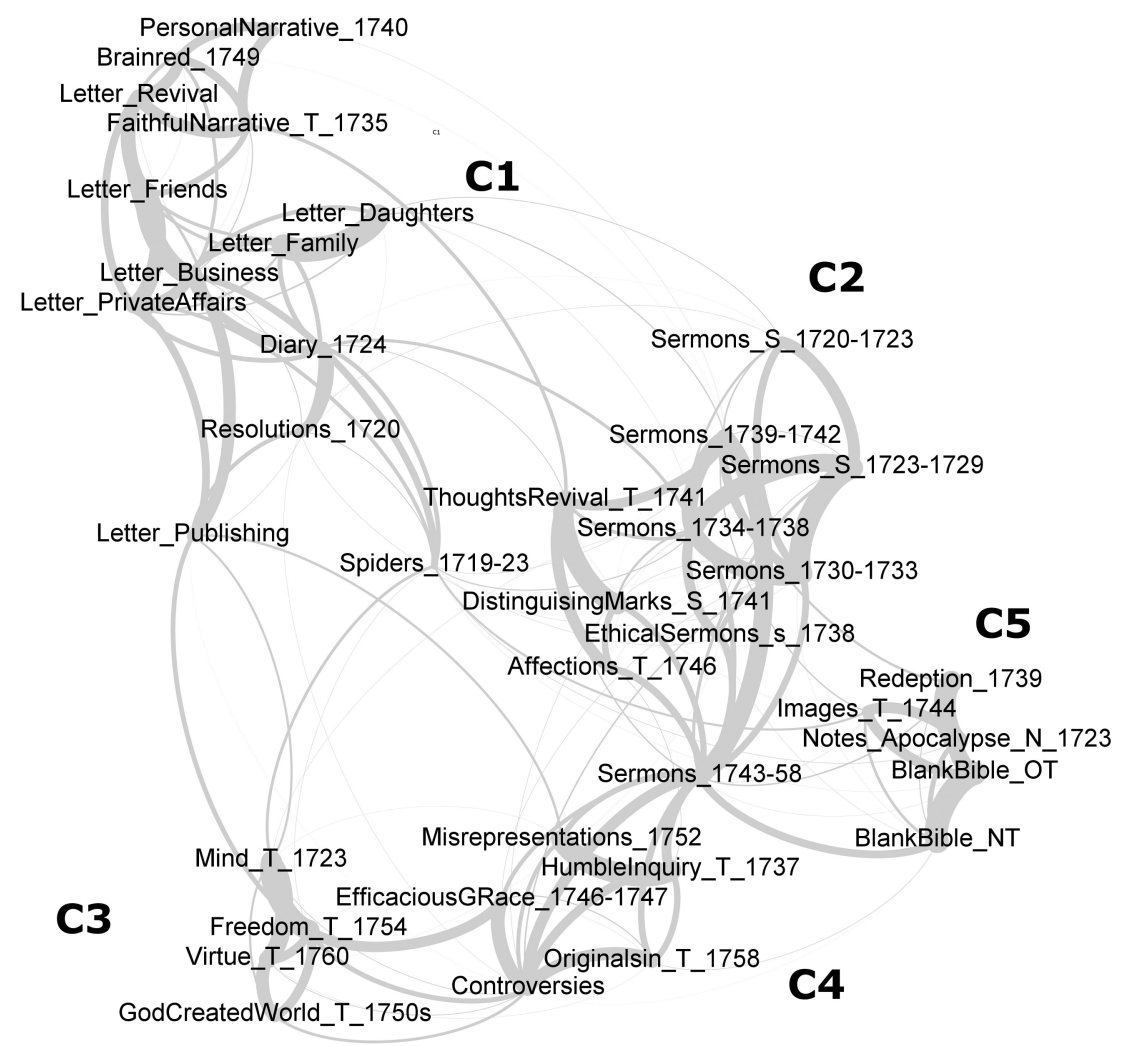

Figure 2: Network analysis of most-frequent-word usage in the works of Jonathan Edwards.

respondence concerning his business and publishing affairs. Also, Edwards's early account of the Northampton revival was incorporated into this cluster. Thus, in terms of the stylometric signal, the "private" Edwards communicating his common problems and concerns, using ordinary, concrete phrases, coalesces with the "pulpit" Edwards, describing religious experiences, and becomes distinctively separate from the "public" Edwards of his other published writings.

The whole $\mathrm{C} 1$ cluster also seems to be separate in terms of genre, as most of the elements incorporated into this first group are epistolary texts. One can argue that it is not only that Edwards's language used for writing about his personal affairs is distinct from the language he employed in his pulpit oratory, but also the sheer convention of letter-writing dictated the employment of different sets of vocabulary or syntax and contributed to this group's visibly salient character. The letters most removed from the group are the ones Edwards exchanged in connection with his publishing plans, mainly with Thomas Foxcroft, his edi- 
tor. Here, the language employed by the preacher, on account of him making references to the texts he was working on in the publication process, understandably drives the epistles towards the said publications. At the same time, Edwards's Diary, his writings on spiders, as well as Resolutions-all three being some of the earliest texts in the whole corpus-although ranked in this first group, seem to drift to the right of the diagram, in the direction of other clusters, forming a bridge between the "private” Edwards and Edwards's second distinct group of texts (C2).

This second cluster of Edwards's writings also bears distinct genre marking, as it is comprised almost exclusively of his sermons. The pulpit oratory of the Northampton minister constitutes the most prominent element of the corpus, both in terms of the number of publications as well as their significance. At the same time, it is this cluster that allows one to look into the chronological changes in Edwards's writing and to trace the evolution of his written word. Edwards's earliest sermons, written between 1720-1723, are the most remote from the group, as they gravitate towards the top of the diagram, away from all the other texts. This, however, changes when one looks at his later writings. Other sermonic elements of the corpus, written in the successive time periods, gradually drift towards its center, allowing us to see the chronological sequence: sermons dating to 1723-1729 follow the earliest collection of texts, and are set adjacent to those from 1739-1742, the time of the initial stage of the Great Awakening. The sermons of 1730-1733 disrupt the clear chronology (as ideally they should have followed the 1723-1729 group), but at the same time they bear a direct individual connection to the pulpit oratory from before that period. At the same time, the groups of sermons from 1734-1738 and the Great Awakening discourses drift towards the location between the outermost elements of groups, revealing a discernible stylometric resemblance.

There are two texts which disrupt the otherwise homogenously sermonic character of the C2 cluster: Thoughts Concerning the Revival and Religious Affections. One would expect them to appear in the treatise groups; it turns out that in terms of the stylometric signal, both these texts more closely resemble Edwards's pulpit oratory than the language employed in his treatises. The theme they touch upon may be partially responsible for their location on the stylometric diagram. Since these two publications of Edwards are thematically connected with the Great Awakening, it is hardly surprising that they exhibit such strong connections with other texts on revivalism, such as the awakening sermons. On the other hand, the sheer thematic resemblance cannot sufficiently explain their location on the diagram. It would seem that Edwards indeed had a unique manner 
of writing about the religious awakening, and the "rhetoric of the revival" ${ }^{34}$ he employed to discuss the mass conversions through the "New Birth," as well as religion directed by affections, leaves a traceable stylometric fingerprint. Edwards's Ethical Sermons was also ranked into this group, relatively close to his treatise on religious affections, as well as Distinguishing Marks, a treatise-like sermon that constitutes perhaps the most powerful endorsement of colonial revivalism.

There is one small group of sermons that drifts away from the center of the preaching cluster, namely Edwards's pulpit discourses published between 17431758. These late sermons visibly diverge towards the stylometric signal of philosophical and theological writings, nonetheless retaining a strong, individual link with the collection of sermons of the Great Awakening, published between 17391742 (thus reflecting their chronological affinity). This can be read as a signal that just as the earlier revival sermons exhibited links to Great Awakening writings, so the mature sermons bear a stylistic affinity to the philosophical texts written by Edwards in the same period of time. The stylometric results might then suggest that the extensive work on the publications Edwards was preparing for printing visibly impacted his sermon-writing and would thus explain the evolution of his preaching style.

In spite of the fact that both the clusters of letters (C1) and sermons (C2) include elements that are not representative of the genre (e.g., Faithful Narrative for letters and personal writings, and Thoughts Concerning the Revival for sermons), there is a distinct stylometric signal of the "pulpit" Edwards and the "private" Edwards. The former, however, seems more distinct, as most elements within this cluster are placed relatively close on the stylometric diagram, and there are strong individual connections between the constituent elements of the group (e.g., between sermons dating to 1730-1733 and 1739-1743 or 1734-1738 and 1723-1729). Also, the stylometry of the preaching texts clearly exhibits a chronological progression in the evolution of Edwards's sermon-writing, as over the years they seem to become gradually more and more treatise-like.

Other writings by Edwards do not exhibit such uniformity or chronological arrangement; in terms of the stylometric signal, Edwards's treatises can be divided into two small sub-clusters. One of them (C3) incorporates his early The Mind and some monumental works he wrote during his mission in Stockbridge: Freedom of the Will, The Nature of True Virtue, and The Reason Why God Created the World. The other one (C4) includes Original Sin (also completed at Stockbridge), Efficacious Grace, Controversies, and An Humble Inquiry.

34 Cf. Choiński, The Rhetoric of the Revival, 216. 
The last cluster of Edwards's texts (C5) that have their own distinct stylometric signal include such writings as Notes on Redemption, Images of Divine Things or The Blank Bible. These texts seem to distance themselves from his other philosophical and theological writings, and gravitate towards Edwards's sermons on the one hand, and, on the other, towards his biblical commentaries. At the same time, they retain a salient stylometric signal, proving there is a stylistic affinity between them, perhaps conditioned by their intertextual connections with Scripture.

\section{Thomas Foxcroft and Jonathan Edwards}

The third experiment conducted as part of the OPUS research grant consists in the study of the extent to which Jonathan Edwards's writings were informed by his literary agent and editor, Thomas Foxcroft. ${ }^{35}$ Such a discussion aligns well with the renewed interest in Edwards not only as a theologian, but also as an American author functioning within colonial print culture. Some recent studies-Peter J. Thuesen's examination of Edwards's book collection ${ }^{36}$ (2008), Wilson Kimnach and Kenneth Minkema's comprehensive study ${ }^{37}$ of Edwards's writing process, and Jonathan M. Yeager's investigation ${ }^{38}$ of Edwards in the context of the contemporary book market-prove that there is yet a lot to be told about the quotidian functioning of religious writings for American colonies.

This time, the measurement of the respective strength of the stylometric signals of Edwards and Foxcroft focused on individual works to find out which portions retain the stylometric thumbprint of the former, and which exhibit patterns of most-frequent-word usage more characteristic of his editor. This procedure, first described by Eder, ${ }^{39}$ relies on samples from the two authors' individual

35 An extended version of our research has been published with a special issue of Amerikastudien, dedicated to the application of Digital Humanities to American Studies (Choiński, Rybicki 2018). The overview below demonstrates one element of the full study and concerns only one book by Edwards, The Humble Enquiry.

36 Peter J. Thuesen, "Introduction," in The Works of Jonathan Edwards, ed. Peter J. Thuesen, vol. 26 (New Haven: Yale University Press, 2008), 1-113.

37 Wilson H. Kimnach and Kenneth P. Minkema, "The Material and Social Practices of Intellectual Work: Jonathan Edwards's Study,” The William and Mary Quarterly 69, no. 4 (2012): 683730, https://doi.org/10.5309/willmaryquar.69.4.0683.

38 Jonathan M. Yeager, Jonathan Edwards and Transatlantic Print Culture (New York: Oxford University Press, 2016).

39 Maciej Eder, “Rolling Stylometry," Digital Scholarship in the Humanities 31, no. 3 (September 1, 2016): 457-69, https://doi.org/10.1093/llc/fqv010. 
works and compares these to 5000-word sections ${ }^{40}$ of those texts by Edwards which are known to have been edited and/or published by Foxcroft.

Historical evidence strongly encourages such investigation. During his service in Northampton and Stockbridge, Edwards relied on Foxcroft's expertise as an editor and literary agent for many of his canonical works, like An Humble Inquiry (1749), Freedom of the Will (1754), and Original Sin (1758). Edwards placed great trust in Foxcroft's erudition and skill to carry out corrections as he intended them. As Yeager emphasizes, when one considers "Edwards's meticulous nature and high standards, it is remarkable how liberal was the dose of trust and flexibility that he dished out to his friend when it came to overseeing the publication of his manuscripts." 41 Edwards's editor sometimes implemented his corrections verbatim, exactly as indicated by the author; at other times, he paraphrased them while preserving what he believed to be the author's idea. Also, Foxcroft's assistance was not limited to the editing of the manuscript only-Edwards entrusted him also with supervision of the entire publication process.

Thus, given the close and prolonged nature of their cooperation, Foxcroft's impact on Edwards's writings demands a detailed investigation-in which the means offered by DH can be of considerable help. Thus, An Humble Inquiry, a text known to be the object of their cooperation, was selected as the object of inquiry for the third experiment. The manuscript of this text was written by Edwards in the spring of 1749. It includes a vigorous defence of Edwards's restrictive church policy, which opposed the idea of open church admission propagated by Solomon Stoddard, as mentioned in the previous sections of this essay. The Northampton minister addresses here the arguments of the lenient church thinkers, protesting against the doctrine of visible sainthood his grandfather was an advocate of.

In An Humble Inquiry, there are some fragments that exhibit Foxcroft's distinct authorial signal (these are marked light grey in Figure 3). As we discuss in the full report of our research on Edwards and his editor, ${ }^{42}$ the first section of the text that can be attributed stylometrically to Foxcroft appears in Part II, beginning with " 'Tis evident, that 'tis not only a visibility of moral sincerity in religion ...” (196), and continues until the paragraph that opens with "But the New Testament affords no more foundation for supposing two real and prop-

40 The length of 5000 words is generally considered promising in terms of statistical significance (cf. Maciej Eder, "Does Size Matter? Authorship Attribution, Small Samples, Big Problem").

41 Yeager, Jonathan Edwards and Transatlantic Print Culture, 96.

42 Michał Choiński and Jan Rybicki, "Jonathan Edwards and Thomas Foxcroft: Pursuing Stylometric Traces of the Editor,” Amerikastudien 63, no. 2 (2018): 153. 


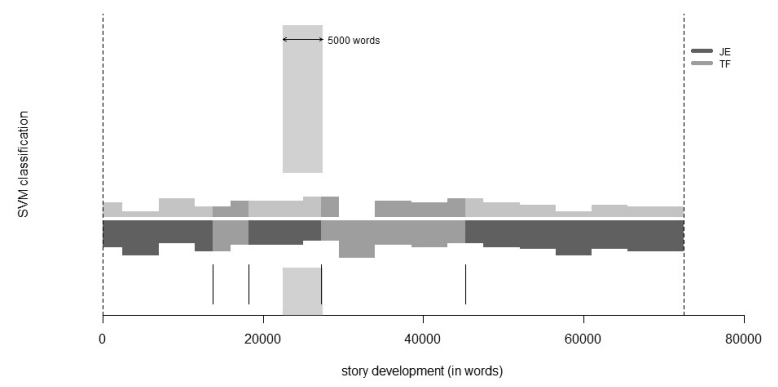

Figure 3: Analysis of "An Humble Inquiry" showing the presence of Foxcroft's stylometric signal in Edwards's text (Edwards: black; Foxcroft: grey). The horizontal line marks the course of the text analysed from the first to the last word. Of the two bands above it, the stronger signal is indicated by the band closer to the axis.

erly distinct covenants of grace, than it does to suppose two sorts of real Christians; the unscripturalness of which latter hypothesis I observed before" (206). The second section potentially 'contaminated' by Foxcroft occurs in the very same part of the treatise, only a few paragraphs later. It begins with the sentence "The same is manifest by the parable of the ten virgins, Matthew 25" (226) and continues to the very beginning of "Part III: Objection Answered." Here, too, stylometric evidence implies that these sections of An Humble Inquiry may be attributed to Foxcroft instead of Edwards-or, at least, that the former's editorial changes are so extensive that they heighten his stylistic signal at the expense of the latter's original text. Both above sections support Edwards's agenda, which was also supported by Foxcroft-they are aimed at supporting his claim that only the visible saints should be admitted to the visible church, and that it is the duty of every Christian to seek to maintain the covenant.

In the abundant correspondence between Edwards and his editor, one can find little to explain the latter's presence in the text. In a letter written shortly before An Humble Inquiry was to be sent to the printer, Edwards included some last-minute changes to Part III of the manuscript. He also asked Foxcroft to incorporate one fragment into the text, which his editor did, almost verbatim, with minor alterations in punctuation, one minor stylistic alternation of word order, and one change of past tense to present tense: from Stoddard "often taught his people that assurance was attainable" to "often taught his people that assurance is attainable" (Letters 287). These alterations could hardly be considered anything more than cosmetic. Thus, the existing correspondence between Edwards and Foxcroft on An Humble Inquiry does not account for the 
strong and consistent presence of the editor's stylometric signal demonstrated in Figure 3. The implication is that, perhaps, Foxcroft's alterations were either discussed in correspondence not included in the surviving letters or were unsolicited by the Northampton preacher.

\section{Coda}

The presentation of the above three experiments is to demonstrate the kind of research that could be conducted with the help of stylometry. In general, the combination of qualitative and quantitative approaches in the OPUS project allowed for a broader outlook on the cultural background of colonial religious discourse-although the results of the research presented above cannot be considered ground-breaking. Still, they were not meant to be. In the case of Jonathan Edwards, the results of this initial stylometric foray make sense when seen in the context of everything that is known, and much indeed is known, of his life and work. Yet there is another end to this stick: since there is so much apparent agreement between the existing biographic/literary/religious/philosophical knowledge on Edwards, the places where stylometry refuses to agree might be worth re-examining by means of traditional scholarship, which might want to explain-to provide but one example-the stylometric migration of some of his sermons towards some of his treatises.

For stylometry must always remember to return to the very texts from which it seems to depart when reaching for mathematical and statistical methods. After all, diagrams of linguistic features alone are irrelevant when dealing with data from the humanities. There is meaning behind the numbers; this meaning must be elicited, and this cannot be done without a marriage of the qualitative with the quantitative. This is why application of statistics to style (or literary history, or genre studies) is best served when the stylometrist collaborates with the literary scholar, the statistician with the historian, in a mood of mutual respect. Thus, apart from the particular collection of texts studied, this project could also constitute an interesting experiment in method. It could help produce the longawaited connection between traditional literary analysis (such as rhetorical or stylistic) and quantitative tools so far used in linguistics rather than literary studies. In this respect, the project strove to address the problem in a recent paper coauthored by a member of our team, stylometrist Rybicki (but the statement itself came from his co-author, a traditional stylist):

It seems (that) stylistics should learn how to use the findings of stylometric analysis not only in hope of arriving at some answers but also at new questions; it would help if styl- 
ometry could learn to better understand the exact mechanisms that make it so successful a tool of authorial attribution even when the author seems to be concealed by the many possible distortions that translation brings about to word frequencies. And while stylometry and stylistics, despite their similar-sounding names, continue to meet across a deep abyss, this just might be-with a little effort on both sides of the abyss-'the beginning of a beautiful friendship. ${ }^{43}$

43 Jan Rybicki and Magda Heydel, "The Stylistics and Stylometry of Collaborative Translation: Woolf's Night and Day in Polish," Literary and Linguistic Computing 28, no. 4 (December 1, 2013): 708-17, https://doi.org/10.1093/llc/fqt027. 